OBSERVAÇOES SOBRE O COMPORTAMENTO DE POPULAÇŌES DE PROTOZOÁRIOS

CILIADOS DO RÚMEN DE CAPRINOS

(CAPRA HIRCUS L.), CRIADOS EM

ITAPETININGA, SĀO PAULO*

MARIA ELY MISEROCHI DE OLIVEIRA

Professor Assistente Doutor

Instituto de Ciências Biomédicas da USP

JOSE CARLOS MACHADO NOGUEIRA FILHO

Professor Assistente Doutor

Faculdade de Medicina Veterinaria e Zootecnia da USP

\section{CARLOS DE SOUSA LUCCI}

Professor Titular

Faculdade de Medicina Veterinaria e Zootecnia da USP

OLIVEIRA, M.E.M.; NOGUEIRA FILHO, J.C.M.; LUCCI, C.5. Observacóes sobre o comportamento de populaças de protozoarios ciliados do rumen de caprinos (Capra hircus L.), criados em I tapetininga, Saro Paulo. Rev. Fac. Med. Vet. Zootec. Univ. S. Paulo, $26(1): 15-20,1989$

RESUMO: Quinze caprinos da raca AngloNubiana tiveram o llquido ruminal colnido quinzenalmente, por meio de sonda esofagiana, desde a nascimento ate completarem 11 meses. Foram executadas medidas de $\mathrm{pH}$ e contagens diferenciais (genericas) dos ciliados presentes por ml de llquido ruminal. Verificou-se que, a partir do $3^{0}$ mês, é consistente a presenca da fauna ruminal, atingindo a contagem global o total de $7,66 \times 10^{3}$ $1 \mathrm{ml}$ ciliados, com pH de 5,8. A tendência à estabilizaça da fauna ocorreu a partir do $10^{\circ}$ mês, com pH de 6,9 e com as seguintes ndmeros: Total de ciliados: $217,02 \times 10^{3} / \mathrm{ml}$; Entodinium sp: 151,68 $\times \quad 10^{3} / \mathrm{ml} ;$ Diplodinium sp: $55,68 \times 10^{3}$ /ml; Epidinium sp: $4,38 \times 10^{3} / \mathrm{ml}$; Isotricha sp: $1,51 \times 10^{3} / \mathrm{ml}$; Dasytricha sp: $3,79 \times 10^{3} \quad / \mathrm{mL}$. As porcentagens respectivas sobre o total verificado foram: 69,88\%; $25,66 \% ; \quad 2,01 \%$; $0,69 \%$; $1,74 \%$.

UNITERMOS: Rumen, caprinos; Protozoa

\section{INTRODUCAO E LITERATURA}

0 desenvolvimento e a instalaça de uma populaça constante de ciliados, no rumen de animais jovens, tem sido alvo de diversas pesquisas, no Brasil (NOGUEIRA FILHO et ali i, 8,9); OLIVEIRA et a(ii, 10), dado o interesse em se conhecer a sua participaça na degradacâo ruminal das celulas vegetais.

Em 1843, GRUBY \& DELAFOND, 5 descobriram a presenca de ciliados no rumen; no inlcio deste século, CUNHA, 1 cataloga e classifica ciliados de bovinos e caprinos, enumerando 14 diferentes especies.

No presente trabalho, procurou-se acompanhar o desenvolvimento numerico dos ciliados ruminais, distribuldos em gêneros, dentro dos criterios de GALL \& HUHTANEN, 4; HUNGATE, 7 ; DEHORITY, 2.

EADIE, 3 verificou que especies de diferentes gêneros, em hospedeiros diferentes, embora sob dieta idêntica, apresentaram populaçôes ruminais diferentes. RAI \& PANDEY, 11, pesquisando em caprinos submetidos a racoles com diferentes concentraçăes de nitrogênio, năo acharam diferencas nas contagens totais de ciliados do rumen.

SONI \& SHARMA, 12, também em caprinos, verificaram aumento no numero de ciliados, com a elevacao da concentraça proteica da raça. Seus resultados medios em termos percentuais foram: Holotricha sp. 4,92\%; Entodinium sp. 64,72\%; Diplodinium sp. 13,7\%; Polyplastron sp. e outros 16,85\%

Nesta pesquisa, verificaram-se os numeros médios dos representantes dos gêneros mais comuns de ciliados ruminais: Entodinium, Diplodinium, Epidinium, Isotricha, Dasytricha, em caprinos manejados em regime de pastejo.

\section{MATERIAL E METODOS}

A pesquisa foi realizada no Posto Experimental de Ovinos e Caprinos de Itapetininga do Instituto de Zootecnia da Secretaria de Agricultura de Săo Paulo. Está situado a $23^{\circ} 35^{\prime}$ de latitude sul e $48^{\circ} 02^{\prime}$ de longitude oeste, numa altitude de $636 \mathrm{~m}$. O clima da regiao e classificado como sendo do tipo cfa, segundo a classificacão de Koeppen

Foram utilizados 15 caprinos da raca Anglo-Nubiana ( 12 machos e 3 fémeas) desde seu nascimento ate atingirem 11 meses de vida. Estiveram submetidos ao seguinte manejo: nos primeiros 15 dias, apds o nascimento, foram mantidos

* Trabalho realizado com o auxilio da Fundaçẫo de Amparo à Pesquisa do Estado de São Paulo (FAPESP).

Apresentado ao X Congresso da Sociedade Brasileira de Parasitologia - Salvador Bahia: 02 a 06 de agosto/87. 
em baias cobertas, recebendo, nos cochos, concentrado e capim Napier (Pennisetum purpureum) picado. Mamaram o colostro de suas matrizes e, ainda, recebiam leite oferecido em mamadeiras. Das 10 as 13 horas, eram levados para piquetes com predominância de capim Pangola (Digitaria decumbens), separados das matrizes, com o proposito de tomarem sol.

Com 15 dias, 05 cabritos foram separados das matrizes, continuando a receber leite, na quantidade de 0,3 a 0,4 litros, diariamente, as 7:00 horas, mantendo-se a rotina anterior. O teor da proteina bruta na mistura concentrada oferecida ( $80 \%$ de espiga de milho, 19\% de farelo de $50 j a$ e $1 \%$ de mistura mineral) foi igual a 12\%. Seu consumo, em quantidade apreciácel, ocorreu depois de 30-95 dias de vida.

0 desaleitamento foi praticado aos 4 meses de idade, quando se realizou a separacão de machos e fêmeas. Estas permaneceram com o plantel de cabras, em pastos de capim Pangola, das 7 às 16 horas, quando eram recolhidas no capril, onde tinham, à disposicaro, capim Napier picado e sal mineral. Os machos permaneceram separados, em piquetes de capim Pangola, sendo recolhidos ao anoitecer, com o mesmo tratamento oferecido ás cabritas. Machos e fêmeas continuaram recebendo concentrado (100 gleabecal dia).

As amostras de Llauido ruminal eram colnidas com o emprego de sonda esofagiana, sempre no perlodo matinal e com intervalos de 14 dias. O procedimento dessas colheitas foi o mesmo ja descrito em trabalho anterior (OLIVEIRA et ali $i$, 10); o pH, nas amostras coltidas, era determinado no momento da colheita. As contagens de ciliados foram efetuadas de acordo com procedimento de DEHORITY, 2 .

A andise estatistica foi elaborada sobre os resultados médios de cada 28 dias (abrangendo 2 colheitas consecuti vas). O modebo matematico empregado foi - de Análise da Regressao Năo-linear (HOFFMAN \& VIEIRA, G), sendo a funcra utilizada para o ajuste das medias de ciliados por ml de liquido ruminal, em funcaro do tempo.

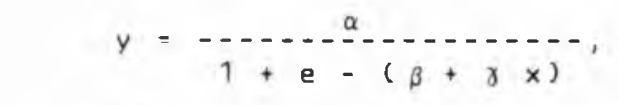

onde $y$ = numero médio de protozoários ciliados

$x=$ tempo (meses)

e $=$ exponencial

$\alpha, \beta$ e $\gamma=$ parametro das funças $\alpha>0 e_{\gamma}>0$ $\alpha=$ assintota horizontal ou numero maximo de protozoarios ciliados.

\section{RESULTADOS E DisCU5SRO}

A Fig. 1 mostra o numero medio total de ciliados por ml de liquido ruminal, nos caprinos em ambos os sexos, versus idade (em meses).

As contagens foram realizadas para - total de ciliados, como para as especies, a partir do $3^{0}$ mês para Entodinium 5p.; de $4^{\circ}$ meses para Diplodinium sp.; de $5^{\circ}$ meses para Epidinium sp. e Dasytricha sp.; de $6^{\circ}$ meses para Isotricha sp.

A Tab. 1 revela a analise de regressão năo linear e coeficiente de determinaça $\left(r^{2}\right)$ de ciliados do rumen; a Tab. 2 fornece valores encontrados, conforme a idade, para os diferentes gêneros, bem como os valores de $\mathrm{pH}$.

As Fig. 1 e 2 mostram os numeros medios, respectivamente, do total de ciliados e de Entodinium sp. por ml de liquido ruminal versus idade, em meses.

As amostragens de 14 e 28 dias de idade não apresentaram ciliados, observaça esta concorde com as de EADIE, 3 ; NOGUE IRA FILHO et alii, 8,9; HUNGATE, 7; no caso dos nossos caprinos, as observacoues de 42 e 56 dias tambem năo mostraram presenca de ciliados, embora o oH ruminal fosse de 5,0 .

0 atraso que se constatou no aparecimento de ciliados no rumen de caprinos, em relaça ao de ovinos (DLIVEIRA et alii, 10 e a de bezerros (NOGUEIRA FILHO et alii, 8, 9) pode ter ocorrido, ao menos em parte, devido à separacro entre cabritos e matrizes, apos o $15^{\circ}$ dia de vida. Seria interessante descobrir se, alterando o manejo, permanecendo os cabritos com as matrizes por mais tempo, haveria possibilidade de colonizaço mais rápida. Nos trabalhos de NOGUEIRA FILHO et alii, 8, 3, com bezerros, estes animais foram separadas das mâs o mais tardar no $3^{0}$ dia de vidae, no entanto, o aparecimento de ciliados em seus rumens ja era patente aos 2 meses.

E curioso registrar que Entodinium sp. apareceu em bom numero por mb de liquido ruminal, em caprinos, a partir do $3^{\circ}$ més de vida, quando o pH do llquido era de 5,8, em media. Nos ovinos (OLIVEIRA et alii, 10) Entodinium sp. apareceu em numero consideravel aos 2 meses de vida, com pH ruminal de 6,1 .

A analise estatlstica dos dados permitiu registrar que a estabilizaca do numero de ciliados por ml de liquido ruminal ocorreu no $10^{\circ}$ més de vida (Fig. 1 e 2).

Entodinium sp. concorreu sempre, pelo menos, com 77,6\%, em media, do numero total de ciliados.

Apos a estabilizaço, 05 numeros medios de protozoários foram: Entodinium sp.; $151,66 \times 10^{3} / \mathrm{ml}$; Diplodinjum sp.; 
Observaçoes sobre o comportamento de populações de protozoários ciliados do rúmen de caprinos

$55,68 \% \times 10^{3} \mathrm{lml}$; Epidinium sp.; 4,38\% $\times$ $10^{3} / \mathrm{ml} ;$ Isotricha sp.; $1,51 \times 10^{3} / \mathrm{ml}$; Dasytricha sp.; $3,73 \times 10^{3} / \mathrm{ml}$, num total de ciliados de $217,02 \times 10^{3} \mathrm{lml}$, nas porcentagens respectivas de 69,88\%; $25,65 \% ; \quad 2,01 \% ; 0,69 \%$ e $1,74 \%$, com um $\mathrm{pH}$ de 6,91. Estes dados, comparados com os de SDNI \& SHARMA, 12 revelaram-se superiores para Entodinium sp. (69,88\% contra 64,72\%), Diplodinium sp. (25,66\% contra 13,74\%) e inferiores para Holotricha (Isotricha sp. e Dasytricha sp.) 2, 43\% contra 4,92\%).

\section{CONCLUSOES}

Nas condiços particulares da presente investigacao, podem ser registradas as seguintes conclusós:

1 - os caprinos comecaram a apresentar fauna ruminal a partir do $3^{0}$ mês de vida, formada sobretudo por protozoarios ciliados do gênero Entodinium, compH de 5,8;

2 - a tendência à estabilizaça da fauna ruminal ocorreu a partir dos 10 meses de idade, com pH de 6,9 e com os seguintes numeros: Total: $217,02 \times 10^{3} \mathrm{lml}$; Entodinium sp.: $151,66 \times 10^{3} / \mathrm{ml}(69,88 \%) ;$ Diplodinium sp.: $55,68 \times 10^{3} / \mathrm{ml}(25,66 \%)$; Epidinium sp.: $4,38 \times 10^{3} \quad 1 \mathrm{ml}$ (2,01\%); Isotricha sp.: $1,51 \times 10^{3}$ $/ \mathrm{ml}(0,69 \%)$; Dasytricha sp.: $3,79 \times$ $10^{3} / \mathrm{ml}(1,74 \%)$.
OLIVEIRA,

M.E.M. :

NOGUEIRA FILHO, J.C.M.; LUCCI, C.S. Observations on the behaviour of ciliated protozoa of the rumen of goats (Capra hircus L.) reared in Itapetininga, Să Paulo. Rev. Fac. Med. Vet. Zootec. Univ. S. Paulo, 26(1):15.20, 1989.

SUMMARY: Samples of rumen contents were colbected by stomach tube from fifteen Anglo-Nubian breed goats, every two weeks, since their birth until the age of eleven months. PH measurements and differential counts (by genera) of the ciliates were performed per milliliter of rumen contents. At the age of three months, the caprines started to show rumen fauna mostly represented by the ciliates of the genus Entodinium, at $\mathrm{pH}$ 5.8. The rumen fauna tended to stabilize after 10 months, with pH 6.9, reaching the following numbers: Total ciliates counting $217.02 \times 10^{3} / \mathrm{ml}$; Entodinium sp., $151.66 \times 10^{3} / \mathrm{ml}$ (69.88\%)); Diplodinium $5 \mathrm{p} ., 55.68 \times 10^{3} / \mathrm{ml}$ ( $25.68 \%)$; Epidinium sp. $4.38 \times 10^{3} / \mathrm{ml}$ (2.01\%); Isotricha sp., $1.51 \times 10^{3} / \mathrm{ml}$ $(0.69 \%) ;$ Dasytricha sp., $3.79 \times 10^{3} / \mathrm{ml}$ $(1.74 \%)$.

UNITERMS: Rumen of goat; Protozoa

TABELA 1 - Análise de regressão nâo-linear e coeficiente de determinaçāo de protozoários do rúmen de caprinos da raça Anglo-Nubiana.

\begin{tabular}{|c|c|c|c|c|}
\hline GENEROS & $\alpha$ & $\beta$ & $\gamma$ & $\begin{array}{l}\text { COEFICIENTE DE } \\
\text { DETERMINACAO }\end{array}$ \\
\hline Entodinium & $150.200,8120$ & $-5,7924$ & 1,0389 & 0,99010 \\
\hline Diplodinium & $58.163,3904$ & $-6,4806$ & 0,9730 & 0,99086 \\
\hline Epidinium & $4.811,1156$ & $-8,9458$ & 1,1171 & 0,98018 \\
\hline Isotricha & $1.523,9108$ & $-6,7828$ & 1,0049 & 0,93859 \\
\hline $\begin{array}{c}\text { Dasytricha } \\
\text { MEDIA }\end{array}$ & $\begin{array}{r}3.774,0739 \\
-\end{array}$ & $-16,1792$ & 2,6781 & 0,97749 \\
\hline AR I TME T I CA & $217.351,2907$ & $-5,6518$ & 0,9543 & 0,99103 \\
\hline
\end{tabular}




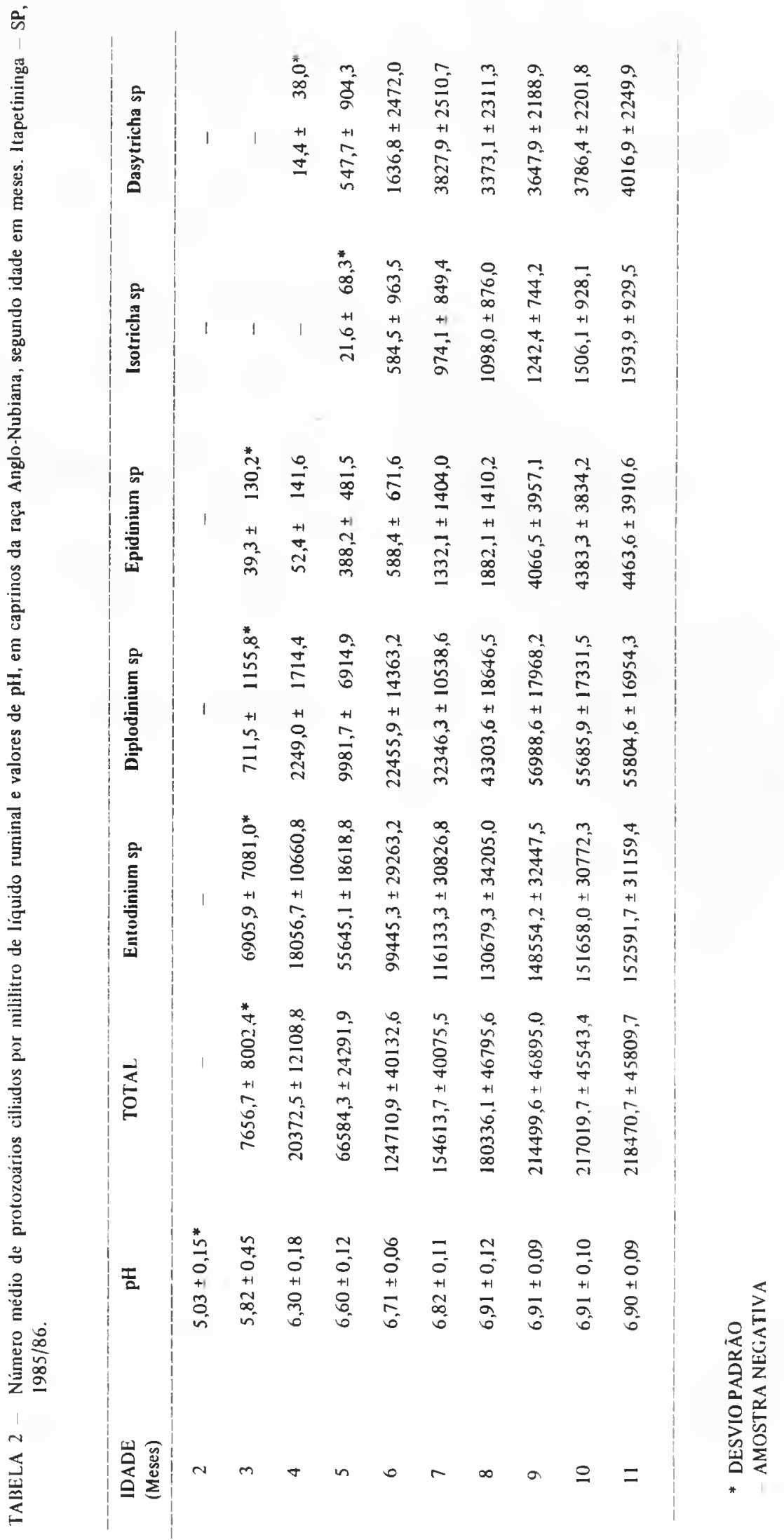


Observaçōes sobre o comportamento de populaçð̄es de protozoários ciliados do rúmen de caprinos

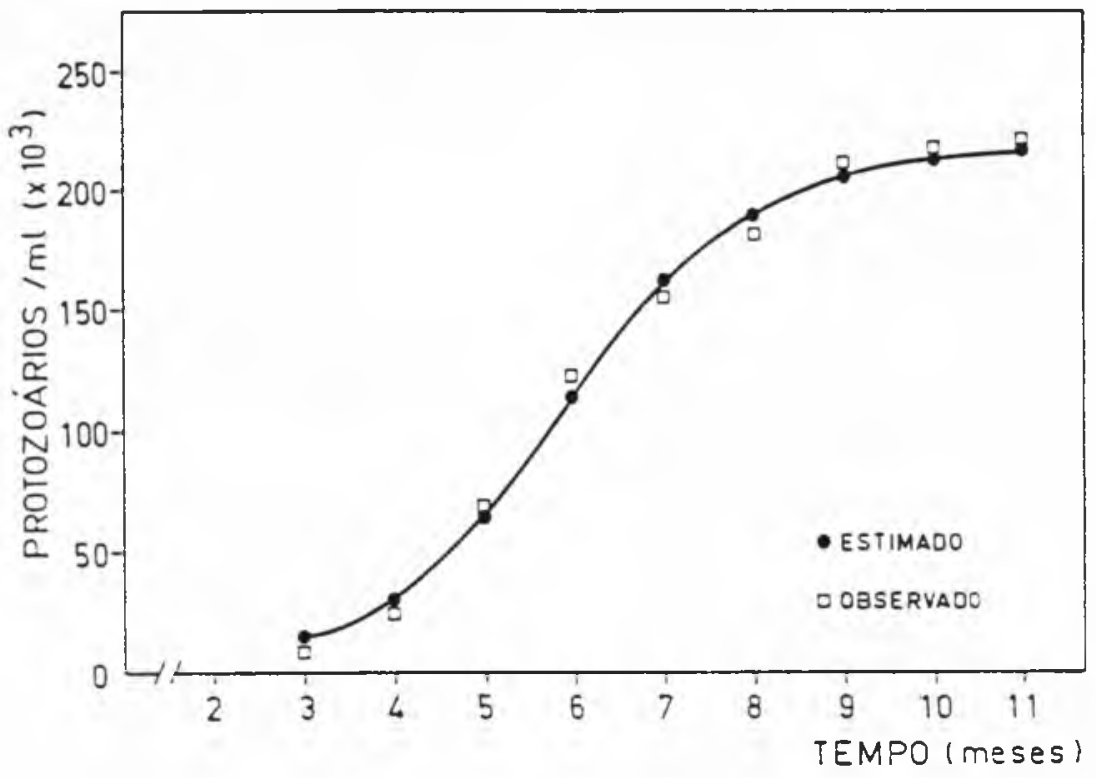

FIGURA 1 - Número médio sobre o total de protozoários por mililitro de liquido ruminal versus idade em meses, em caprinos, da raça Anglo-Nubiana.

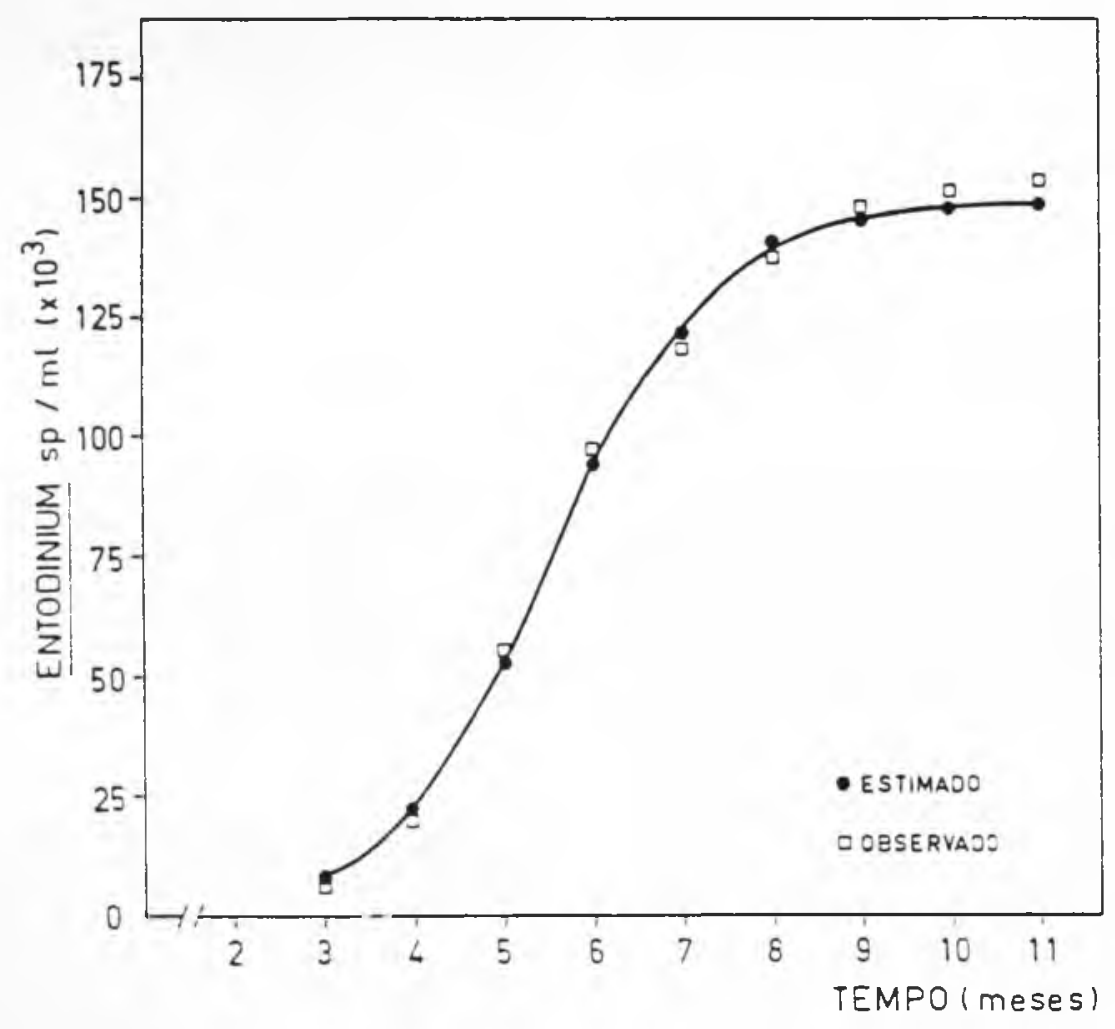

FIGURA 2 - Número médio de Entodinium sp. por mililitro de liquido ruminal versus idade em meses, em caprinos, da raça Anglo-Nubiana. 


\section{REFERENCIAS BIBLIOGRAFICAS}

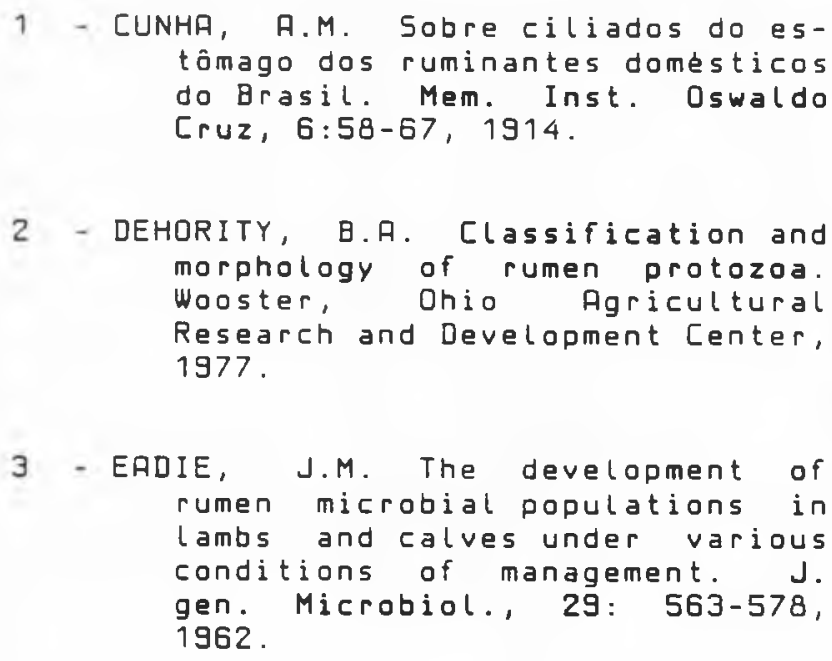
tómago dos ruminantes domésticos do Brasil. Mem. Inst. Oswaldo Cruz, 6:58-67, 1914.

2 - DEHORITY, B.A. Classification and morphology of rumen protozoa. Wooster, Ohio Agricultural Research and Development Center, 1977 .

3 - EADIE, J.M. The development of rumen microbial populations in lambs and calves under various conditions of management. $J$. gen. Microbiol., 29: 563-578, 1962 .

4 - GALL, L.5. \& HUHTANEN, C.N. Criteria of cansidering a bacterium isolated from the rumen as a Bona fide rumen organism. J. anim. Sci., 9:656, 1950.

5 - GRUBY \& DELAFOND apud HUNGATE, 7 p. 2 .

6 - HOFFMANN, R. \& VIEIRA, 5. Analise de regresså: uma introduça à ecometria. 2. ed. Să Paulo. Hucitec, 1983.

7 - HUNGATE, R.E. The rumen and its microbes. New York, Academic Press, 1966.

8 - NQGUEIRA FILHO, J.C.M.; OLIVEIRA, M.E.M. i VEIGA, J.S.M.; LUCCI, C.5. Dbservaçes pertinentes à instalacaro da fauna de protozoarios ciliados no rumen de bezerros de raca Holandesa (Bos taurus L.), eriados em Pindamonhangaba, SP., Brasil. Rev. Fac. Med. Vet. Zootec. Univ. S. PauLo, 20:177-182, 1983.

9 - NOGUEIRA FILHO, J.C.M.; OLIVEIRA, M.E.M.; VEIGA, J.S.M.; LUCEI, C.5. Cronologia do aparecimento de protozoarios ciliados no rumen de bezerros do tipo "Mantiqueira" (Bos taurus L.), na regia do Vale do Ria Paratba, SP. Rev. Fac. Med. Vet. Zootec. Univ. 5. Paulo, 21:119-124, 1984.

10 - Oliveira, M.E.M.; NOGUeira FILHO, J.C.M.; LUCCI, C.S.; DUPAS, W. LIMA, C.G. Desenvolvimento de populações de protozoarios ciliados no rumen de ovinos (Ovis aries L.) criados em Itapetininga, Săo Paulo. Rev. Fac. Med. Vet. Zootec. Univ. 5. Paulo, $24: 225-232$, 1987 .

11 - RAI, G.5. \& PANDEY, M.D. Urea as a protein substitute in the ration of male goats: 1. TUFA, $p H$, buffer capacity of rumen fluid, cellulolysis, gas production, microbial count and enzyme activity. Indian J. anim. Hlth., $22: 51-57,1983$

12 - SONI, U.K. \& SHRRMA, D.D. Note an the influence of levels of concentrate feeding on the microbial population in goat rumen. Indian J. anim. 5ci., 52:831833,1982 .

Recebido para publicaço em $10 / 05 / 88$ Aprovado para publicaça em $04 / 08 / 88$ 